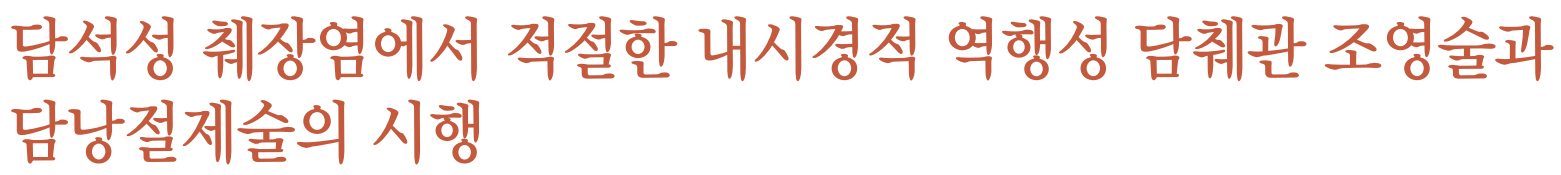

${ }^{1}$ 서울대학교 의과대학 내과학교실 및 간연구소, ${ }^{2}$ 서울대학교병원 내과

최영훈 ${ }^{1,2} \cdot$ 이상협 1,2

\title{
Indications and Timing of ERCP and Cholecystectomy for Biliary Pancreatitis
}

\author{
Young Hoon Choi ${ }^{1,2}$, Sang Hyub Lee ${ }^{1,2}$ \\ 'Department of Internal Medicine and Liver Research Institute, Seoul National University College of Medicine, Seoul; 'Department of Internal \\ Medicine, Seoul National University Hospital, Seoul, Korea
}

In acute biliary pancreatitis, endoscopic retrograde cholangiopancreatography (ERCP) and cholecystectomy should be considered to reduce the complications of gallstones including recurrent biliary pancreatitis. If biliary pancreatitis is accompanied by cholangitis or evidence of obvious biliary obstruction, removal of the common bile duct stone via early ERCP (within 24 to 72 hours) is necessary. Less or non-invasive imaging modalities such as endoscopic ultrasound, magnetic resonance cholangiopancreatography can be considered to avoid unnecessary ERCP if suspected biliary obstruction in the absence of cholangitis in patients with biliary pancreatitis. Cholecystectomy in patients with biliary pancreatitis requires a strategy that varies the timing of surgery depending on the severity of pancreatitis. In mild acute biliary pancreatitis, cholecystectomy can be performed safely at the time of initial admission. In moderate to severe biliary pancreatitis, cholecystectomy should be delayed until about 6 weeks when active inflammation subsides and fluid collections resolve or stabilize. Endoscopic sphincterotomy (EST) can be helpful in reducing recurrent pancreatitis in patients who unfit for cholecystectomy. However, even if EST is performed, additional cholecystectomy will further reduce the risk of recurrent pancreatitis, if possible, it is recommended to undergo a cholecystectomy.

Korean J Pancreas Biliary Tract 2019;24(1):11-16

Keywords: Biliary pancreatitis, Endoscopic retrograde cholangiopancreatography, Cholecystectomy, Indication, Timing

\begin{abstract}
Received Nov. 19, 2018
Revised Dec. 17, 2018

Accepted Dec. 18, 2018
\end{abstract}

Corresponding author : Sang Hyub Lee Department of Internal Medicine and Liver Research Institute, Seoul National University College of Medicine, 101 Daehagro, Jongno-gu, Seoul 03080, Korea

Tel. +82-2-2072-4892 Fax. +82-2-762-9662

E-mail; gidoctor@snuh.org

ORCID: https://orcid.org/0000-0003-2174-9726

\section{서 론}

급성 췌장염의 가장 흔한 원인은 담석증으로, 약 40-70\%가
담석성 췌장염이다. ${ }^{1}$ 증상이 있는 담석증의 약 $5 \%$ 에서 급성 담석성 췌장염이 발생하고, 담석증에서 급성 췌장염의 연간 발생률은 약 $1 \%$ 로 알려져 있다. ${ }^{2,3}$ 급성 담석성 췌장염은 
일반적으로 담석에 의한 유두부(ampulla) 폐쇄로 일어난 췌관 및 담관의 배액장애로 담즙 및 십이지장 내용물의 췌관내 역류, 췌장의 분비 촉진 등으로 인하여 발병하는 것으로 추정된다., 임상적으로 급성 담석성 췌장염의 진단은 급성 췌장염의 원인이 담도계에서 기인한 것으로 추정될 때 내릴 수 있으며, 이러한 경우는 담석, 담즙찌꺼기(biliary sludge), 또는 총담관의 확장이 영상 검사에서 보이는 경우 혹은 담즙 정체 징후가 있는 경우를 들 수 있다. ${ }^{6,7}$ 이런 소견이 명확하지 않고, 췌장염의 다른 특별한 원인이 없는 경우엔 알라닌 아미노전이효소(alanine aminotransferase)가 정상 상한치의 2 배를 넘으면서, 아스파테이트 아미노전이효소(aspartate aminotransferase)보다 높은 경우에도 임상적으로 급성 담석성 췌장염으로 진단할 수 있다. ${ }^{7,8}$ 이렇듯 담도계 문제에 기인한 급성 담석성 췌장염의 치료 시에는 통증 조절, 수액 요법, 전해질 및 대사성 이상 교정과 같은 일반적인 췌장염의 치료에 더하여 내시경적 역행성 담췌관 조영술 (endoscopic retrograde cholangiopancreatography, ERCP)을 통한 총담관 결석 제거를 고려해야 한다. 그러나 급성 담석성 췌장염에서 약 $50 \%$ 까지 담석이 십이지장으로 자발성 배출이 일어나는 것으로 알려져 있어 $\mathrm{ERCP}$ 가 필요하지 않은 경우도 있으며, ${ }^{9,10}$ 치료적 ERCP는 합병증이 7-10\%, 사망률이 $0.2-2.2 \%$ 까지 보고되어 있는 비교적 침습적인 내시경 시술로 급성 담석성 췌장염에서 $\mathrm{ERCP}$ 를 어떤 환자에게 언제 시행할지 결정하는 것은 임상적으로 매우 중요한 문제이다. ${ }^{11,12}$ 또한 급성 담석성 췌장염에서 많은 경우에 담석의 자발성 배출이 일어나긴 하지만 담석증이 치료되지 않는 경우 약 $60 \%$ 까지 재발성 췌장염이 발생할 수 있는 것으로 알려져 있다. ${ }^{13}$ 이러한 재발성 담석성 췌장염의 위험성을 낮추는데 담낭절제술을 시행하는 것이 도움이 된다고 알려져 있으나 그 시점에 대해서는 이견이 있다. ${ }^{14-16}$ 이에 본고에서는 문헌고찰을 통하여 급성 담석성 췌장염 환자에서 ERCP 및 담낭절제술의 적절한 적응증과 그 시점에 대하여 알아보고자 한다.

\section{본 론}

\section{1. 급성 담석성 췌장염에서 조기 ERCP 시행의 유용성}

급성 담석성 췌장염에서 조기(24-72시간 이내)에 $\mathrm{ERCP}$ 를 시행하는 것이 임상적으로 유용한 지에 대하여 여러 건의 전향적 무작위 대조 연구가 시행되었다. Neoptolemos 등근 입원 72시간 내에 $\mathrm{ERCP}$ 를 시행한 경우 급성 담석성 췌장염 환자들에서 합병증 발생률을 낮춰준다는 것을 보고하였고, Acosta 등 $^{18}$ 은
증상 발생 48시간 내에 $\mathrm{ERCP}$ 를 시행한 경우 치료 후 혹은 초기 입원 기간 중에 발생하는 것으로 정의한 조기 합병증의 발생률을 낮춰주는 것으로 보고하였다. 그러나 Fölsch 등 ${ }^{19}$ 이 보고한 전향적 무작위 대조 연구에서는 증상 발현 72시간 내에 $\mathrm{ERCP}$ 를 시행한 군과 대조군 사이에 유의한 합병증 발생의 차이가 없었고, Oría 등 ${ }^{20}$ 이 보고한 연구에서도 증상발현 24-72시간 내에 시행한 ERCP가 합병증 및 사망률을 낮추는 데 기여하지 못하였다. 조기 ERCP 시행이 합병증을 줄이지 못한 Fölsch 등 ${ }^{19}$ 과 Oría 등 ${ }^{20}$ 의 연구에서는 앞선 연구들과 연구 대상자 선정에 있어 차이점을 보이는데, Fölsch 등 ${ }^{19}$ 의 연구에서는 총 빌리루빈이 $5 \mathrm{mg} / \mathrm{dL}$ 이상으로 명백히 담관폐쇄가 의심되는 환자를 연구 대상에서 제외하였으며, Oría 등 ${ }^{20}$ 의 연구에서는 급성 담관염인 환자들을 연구 대상자에서 제외하였다. 이러한 결과는 Tse와 Yuan $^{21}$ 이 급성 담석성 췌장염에서 조기 ERCP 치료와 보존적 치료를 비교한 무작위 대조 연구들을 메타분석한 연구에서도 보여진다. 이 연구에서 전체 담석성 췌장염 환자에 대한 조기 $\mathrm{ERCP}$ 치료와 보존적 치료 간의 사망률, 합병증 발생은 차이를 보이지 않았으나 담석성 췌장염 환자 중 담관염을 동반한 환자의 비교분석에서는 조기 ERCP 치료가 사망률과 합병증의 유의한 감소를 가져오는 것으로 확인되었다. 또한 담석성 췌장염 환자 중 폐쇄성 황달을 동반한 환자들에서는 조기 ERCP 치료를 받은 경우 보존적 치료를 받은 경우에 비하여 국소 합병증이 적게 발생하였다. 이상의 연구들을 바탕으로 담관염을 동반하거나 담관폐쇄가 의심되는 담석성 췌장염 환자에서는 조기에 시행하는 $\mathrm{ERCP}$ 가 보존적 치료에 비하여 임상경과를 호전시킨다는 것을 알 수 있다. 이 때 담관염이나 담관폐쇄가 의심되는 상태는 연구들마다 약간의 차이를 보이나 다음의 내용과 대동소이하다. 발열, 황달, 복통을 포함하는 Charcot triad가 있는 경우엔 담관염으로 진단할 수 있으며 38.5 도를 초과하는 발열이 있으면서 혈청 빌리루빈이 $2.3 \mathrm{mg} / \mathrm{dL}$ 를 초과하거나 영상 검사에서 총 담관이 $8 \mathrm{~mm}$ 를 초과하여 늘어나 있는 경우에 담관염으로 진단할 수 있다. ${ }^{7,82}$ 또한 발열 없이 혈청 빌리루빈 증가 $(>2.3$ $\mathrm{mg} / \mathrm{dL})$ 나 영상 검사에서 총 담관 확장 $(>8 \mathrm{~mm})$ 소견이 있는 경우 담관폐쇄를 의심할 수 있다. 다음으로 담석성 췌장염 환자에서 얼마나 이른 시기에 $\mathrm{ERCP}$ 를 시행하는 것이 가장 도움이 될 것인지가 임상적 결정을 내리는데 필요한 정보이다. 이를 위하여 현재까지 조기 ERCP와 보존적 치료를 비교한 무작위 대조 연구들을 살펴보면 총 8 건으로 Table 1 에 그 내용이 요약되어 있다. Table 1에서 살펴볼 수 있듯이 각각의 연구에서 $\mathrm{ERCP}$ 를 시행한 시기는 24-72시간 이내로 다양하고, 그 시작 시점도 증상 
발생부터인지 입원부터인지가 연구마다 제각각이어서 이를 바탕으로 얼마나 이른 시점에 $\mathrm{ERCP}$ 를 시행하는 것이 더 좋은지에 대한 결론을 내리기는 어렵다. Table 1에 요약된 총 8건의 무작위 대조 연구를 체계적 문헌고찰(systematic review)을 통하여 분석한 결과에서 급성 담석성 췌장염에서 조기 $\mathrm{ERCP}$ 는 사망률, 기관 부전(organ failure), 괴사성 췌장염 등에 차이를 보이지 못하였고, 단지 한 건의 연구에서 입원 기간의 감소에만 영향을 주는 것으로 나타났다. ${ }^{23}$ 이를 바탕으로 작성된 최근의 가이드라인에서도 담관염을 동반하지 않은 급성 담석성 췌장염에서 일괄적인 조기 $\mathrm{ERCP}$ 의 시행은 권고되지 않고 있다고 하였으나 조기 ERCP의 시점에 대한 언급은 없다. ${ }^{24}$ 다만 8 개의 무작위 대조 연구 중에 $\operatorname{Fan}$ 등 $^{25}$ 의 연구에서는 입원 24 시간 내에 $\mathrm{ERCP}$ 를 시행한 경우 유의하게 담도계 패혈증이 적게 발생했다는 보고가 있어 특히 담관염이 동반된 담석성 췌장염에서는 입원 24 시간내 시행하는 ERCP가 도움이 될 수 있겠다.

담관염이나 폐쇄성 황달을 동반하지 않은 급성 담석성 췌장염 환자의 경우 $\mathrm{ERCP}$ 보다는 합병증이 적은 자기공명 담췌관 조영술(magnetic resonance cholangiopancreatography, MRCP) 이나 내시경초음파(endoscopic ultrasound, EUS)를 통하여 총담관 결석을 확인한 후 필요에 따라 $\mathrm{ERCP}$ 를 시행하는 것이 불필요한 $\mathrm{ERCP}$ 를 줄임으로써 잠재적인 이환율 및 사망률을 낮출수 있을 것이다. ${ }^{10,26}$

\section{2. 급성 담석성 췌장염에서 담낭절제술}

급성 담석성 췌장염 환자에서 담낭절제술이 담석성 췌장염을 포함한 담도계 합병증의 재발을 예방하는 효과가 있다고 알려져 있으나 그 시점에 대해서는 이견이 있다. ${ }^{3,27-29}$ 최근의 체계적 문헌고찰에서 담낭절제술을 시행하지 않고 퇴원한 담석성 췌장염 환자의 경우 약 $18 \%$ 정도의 환자에서 반복적으로 담도계 문제가 발생한다는 연구 결과는 조기에 담낭절제술이 필요하다는 주장을 뒷받침한다. ${ }^{28}$ 담낭절제술을 연기하여 시행하고자 하는 주장들은 췌장염의 급성 염증반응 시기를 지나 담낭절제술을 시행하는 것이 보다 안전하고, 더 좋은 수술적 결과를 가져올 것이라는 논리로 실제 연구들에서도 염증반응이 심한 중증의 담석성 췌장염에서 담낭절제술을 조기에 시행한

Table 1. Summary of randomized controlled trials of early endoscopic retrograde cholangiopancreatography in biliary pancreatitis

\begin{tabular}{|c|c|c|c|c|}
\hline Study & Design & ERCP/control & Timing of ERCP & $\begin{array}{l}\text { Key results } \\
\text { ERCP vs. control }\end{array}$ \\
\hline $\begin{array}{l}\text { Neoptolemos et al. } \\
\text { (1988) }\end{array}$ & $\mathrm{RCT}$ & $59 / 62$ & $\leq 72$ hours of admission & $\begin{array}{l}\text { Lower complications in the ERCP group. } \\
17 \text { vs. } 34 \% \text { ( } p=0.03 \text { ) } \\
\text { Shorter hospital stay in the ERCP group. } \\
9.5 \text { vs. } 17.0 \text { days }\end{array}$ \\
\hline Fan et al. ${ }^{25}$ (1993) & $\mathrm{RCT}$ & $97 / 98$ & $\leq 24$ hours of admission & $\begin{array}{l}\text { Fewer biliary sepsis in the ERCP group. } \\
\text { Overall: } 0 / 97 \text { vs. } 12 / 98 \text { ( } p=0.001) \\
\text { Similar overall complications. }\end{array}$ \\
\hline Fölsch et al. ${ }^{19}$ (1997) & $\mathrm{RCT}$ & $126 / 112$ & $\leq 72$ hours of symptoms & $\begin{array}{l}\text { Similar overall complications and mortality } \\
\text { Mortality } 11.1 \text { vs. } 6.3 \%(p=0.10)\end{array}$ \\
\hline Zhou et al..$^{36}(2002)$ & $\mathrm{RCT}$ & $20 / 25$ & $\leq 24$ hours of admission & $\begin{array}{l}\text { Lower complications and cost, shorter hospital stay in patients } \\
\text { with severe attack in the ERCP group. } \\
\text { No differences in patients with } 2 \text { mild subgroups. }\end{array}$ \\
\hline Acosta et al. ${ }^{18}(2006)$ & RCT & $30 / 31$ & $24-48$ hours of symptoms $(n=14)$ & $\begin{array}{l}\text { Shorter period of obstruction ( } p=0.016) \text { and lower rate of } \\
\text { immediate complications }(p=0.026) \text { in the ERCP group. }\end{array}$ \\
\hline Oría et al. ${ }^{20}(2007)$ & RCT & $51 / 52$ & $\begin{array}{l}\leq 24-48 \text { hours of symptoms }(n=46) \\
\leq 48-72 \text { hours of symptoms }(n=5)\end{array}$ & $\begin{array}{l}\text { Similar local complications }(p=0.99) \text {, overall morbidity } \\
\qquad(p=0.80) \text {, and mortality }(p=1)\end{array}$ \\
\hline Chen et al. ${ }^{37}(2010)$ & $\mathrm{RCT}$ & $21 / 32$ & $\begin{array}{l}<24 \text { hours of symptoms }(n=5) \\
24-48 \text { hours of symptoms }(n=10) \\
>48 \text { hours of symptoms }(n=6)\end{array}$ & $\begin{array}{l}\text { Decreased APACHE II score at day } 10 \text { in the ERCP group } \\
(p<0.05) \text {. } \\
\text { No death in the ERCP group vs. } 2 \text { deaths in the control group. }\end{array}$ \\
\hline Yang et al. ${ }^{38}$ (2012) & $\mathrm{RCT}$ & $60 / 60$ & $\leq 72$ hours of symptoms & $\begin{array}{l}\text { Lower complications }(p<0.05) \text {, shorter hospital stay }(p<0.05) \\
\text { in the ERCP group. } \\
\text { No difference in mortality }(p>0.1) \text {. }\end{array}$ \\
\hline
\end{tabular}

ERCP, endoscopic retrograde cholangiopancreatography; RCT, randomized controlled trial; APACHE, acute physiology and chronic health evaluation. 
경우 오히려 이환율이나 사망률을 증가시켰다. ${ }^{30,31}$ 특히, 중등도 이상의 담석성 췌장염 환자에서 가성 낭종이나 체액 고임이 있는 경우엔 가성 낭종이나 체액 고임이 소실되었을 때나 소실되지 않더라도 안정화되어 잘 배액할 수 있는 6주 이상이 지난 시점으로 미루어 담낭절제술을 시행한 경우 조기에 담낭절제술을 시행한 경우보다 패혈증이나 담낭절제술과 관련된 합병증이 적게 나타났다. ${ }^{31}$

최근에 시행된 무작위 대조 연구에서는 초기 입원시, 무작위배정 3 일 이내에 담낭절제술을 시행한 군과 퇴원 후, 무작위배정 25-30일 되는 시점에 담낭절제술을 시행한 군을 비교 분석하였다. 주평가변수인 담석과 관련된 합병증 혹은 6 개월 이내 사망률은 초기 입원시에 담낭절제술을 시행한 군에서 $5 \%$ 로 추후 담낭절제술을 시행한 군의 $17 \%$ 보다 낮게 나타났다(risk ratio $0.28,95 \%$ confidence interval $0.12-0.66 ; p=0.002)$. 또한 양 군의 복강경 수술에서 개복 수술로 전환된 비율이나 수술의 어려운 정도는 유의한 차이를 보이지 않았다. 이 무작위 대조 연구는 중증의 담석성 췌장염 환자를 배제하고, 경증의 담석성 췌장염만을 대상으로 한 연구로 경증의 담석성 췌장염 환자 에서는 초기 입원시에 담낭절제술을 시행하는 것이 유리하다는 것을 알수 있다.

추가로 임상적으로 담석성 췌장염인지 명확하지 않으면서, 원인을 알 수 없는 재발성 췌장염 환자에서도 담낭절제술이 췌장염 재발을 막는데 도움이 될 수 있다. 이전 연구들을 보면
특발성 췌장염의 약 50-75\%가 미세결석이 원인이라는 보고가 있다. ${ }^{32,33}$ 근래 재발성의 특발성 췌장염 환자들을 대상으로 한 전향적 무작위 대조 연구의 결과도 이러한 주장을 뒷받침하는데, 이 연구에서 복강경 담낭절제술을 시행한 경우 그렇지 않은 경우에 비하여 췌장염의 재발이 유의하게 낮았고, 절제된 담낭의 $59 \%$ 에서 담석이나 담즙찌꺼기를 보인 바 있다. ${ }^{34}$ 따라서 임상적으로 담석성 췌장염인지 명확하지 않더라도, 다른 췌장염의 가능한 원인들을 주의 깊게 배제한 경우엔 담낭절제술이 췌장염 재발을 막는 데 도움을 줄 수 있다.

이상을 종합하였을 때, 경증의 담석성 췌장염 환자에서는 가능한 초기 입원시에 담낭절제술을 시행하는 것이 담석과 관련된 합병증의 감소에 도움이 되며 중등도 이상의 담석성 췌장염 환자에서는 활동성의 염증반응이 가라앉은 뒤에 특히 가성낭종이나 체액 고임이 있는 경우 약 6 주 뒤에 담낭절제술을 미루어 시행하는 것이 이환율을 감소시킨다는 것을 알 수 있다.

이처럼 담낭절제술이 담석성 췌장염의 재발을 포함한 담도계 합병증 발생을 줄여준다고 알려져 있으나 기저 질환이나 신체 활동도 저하 등으로 인하여 담낭절제술을 시행받기 어려운 환자들도 있다. 이런 환자들의 경우 내시경적 괄약근절개술 (endoscopic sphincterotomy, EST)이 담석성 췌장염의 재발을 줄이는 데 도움이 된다는 연구 결과가 있다. ${ }^{35}$ 이 연구에서 담석성 췌장염 환자에서 EST 만을 시행한 경우 재발성 췌장염이 발생하는 비율이 $6.7 \%$ 로 EST나 담낭절제술 두 가지 치료를 모두

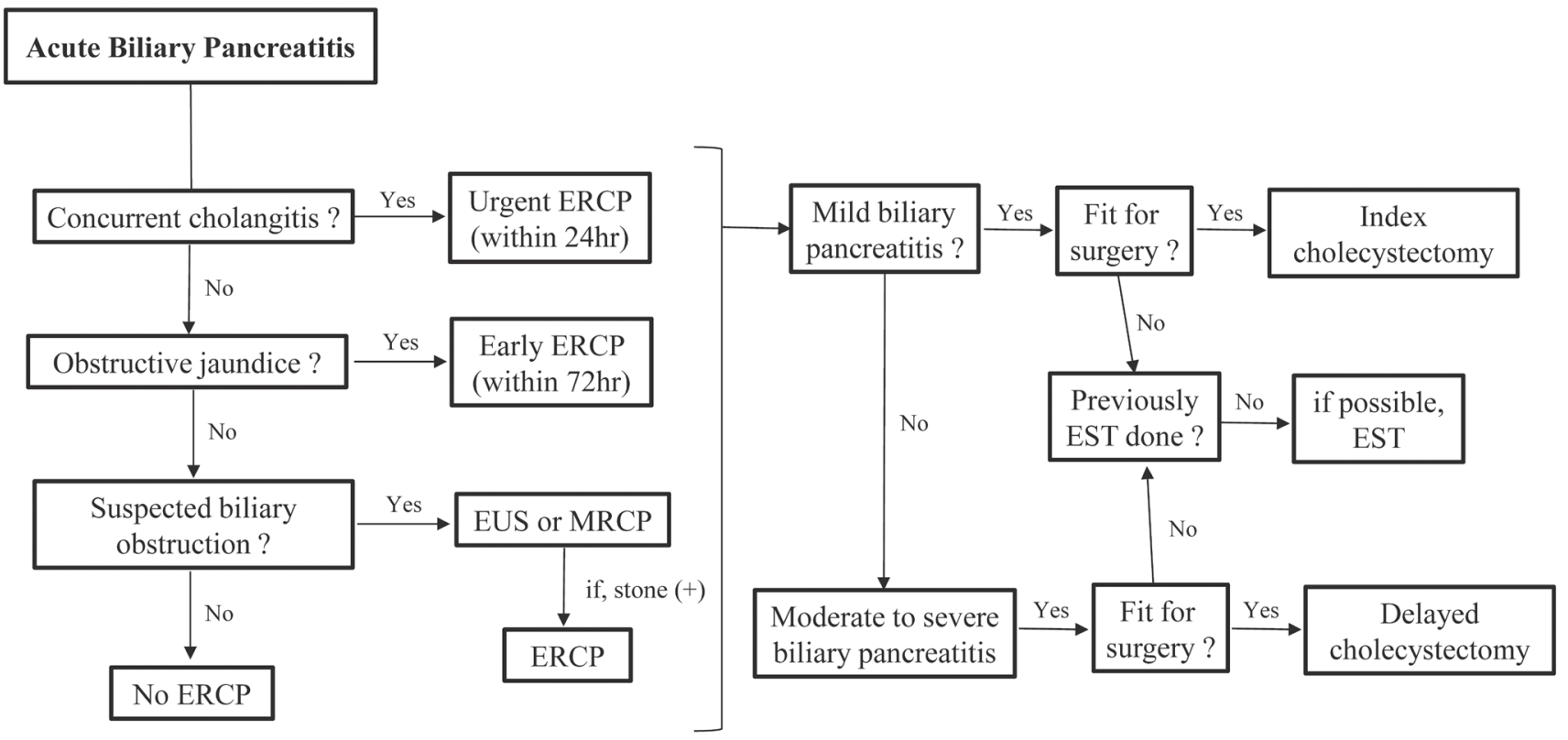

Fig. 1. Schematic presentation of ERCP and cholecystectomy for biliary pancreatitis. ERCP, endoscopic retrograde cholangiopancreatography; hr, hours; EST, endoscopic sphincterotomy; EUS, endoscopic ultrasound; MRCP, magnetic resonance cholangiopancreatography. 
하지 않은 경우의 $14.8 \%$ 에 비하여 유의하게 낮게 나타났으며, EST를 시행한 경우라도 담낭절제술을 추가로 시행한 경우엔 $1.2 \%$ 로 재발성 췌장염의 비율이 더 낮게 나타나 EST를 시행한 경우에도 가능하다면 담낭절제술을 시행하는 것이 좋겠다.

\section{결 론}

급성 담석성 췌장염에서 재발성 담석성 췌장염을 포함한 담석에 의한 합병증을 줄이기 위하여 ERCP 및 담낭절제술의 시행을 고려해야 한다. 담관염이 동반된 경우나 명백한 담관 폐쇄의 증거가 있는 경우엔 조기에 $\mathrm{ERCP}$ 를 통한 총담관결석 제거가 필요하며 그렇지 않은 경우엔 MRCP나 EUS를 통하여 총담관결석이 확인된 경우에 $\mathrm{ERCP}$ 를 시행하는 것이 불필요한 $\mathrm{ERCP}$ 를 통한 잠재적인 이환율과 사망률을 줄일 수 있을 것이다. 또한 경증의 급성 담석성 췌장염에서는 초기 입원시에 담낭 절제술을 시행하여 담석과 관련된 합병증을 줄이고, 중등도 이상의 담석성 췌장염에서는 활동성 염증반응 시기가 지난 뒤에 담낭절제술을 시행하여 이환율을 줄이는 것이 유리하며 담낭절제술 시행이 어려운 환자의 경우엔 EST를 시행하는 것이 재발성 췌장염을 줄이는 데 도움이 된다(Fig. 1).

\section{요 약}

급성 담석성 췌장염에서는 췌장염의 일반적인 치료에 더하여, 재발성 담석성 췌장염을 비롯한 담석에 의한 합병증을 줄이기 위해 내시경적 역행성 담췌관 조영술과 담낭절제술을 반드시 고려해야 한다. 담석성 췌장염에 담관염이 동반되어 있거나 명백한 담도폐쇄의 증거가 있는 경우 24-72시간 이내에 시행하는 조기 내시경적 역행성 담췌관 조영술이 필요하다. 담관염은 없으나 담도폐쇄가 의심되는 경우엔 불필요한 내시경적 역행성 담췌관 조영술을 피하기 위하여, 보다 덜 침습적인 검사 방법인 내시경초음파나 자기공명 담췌관 조영술을 우선 고려해 볼 수 있다. 담낭절제술의 경우 담석성 췌장염의 중증도에 따라 수술 시점을 달리하는 전략이 필요하다. 경증의 담석성 췌장염의 경우, 초기 입원시에 담낭절제술을 안전하게 시행할 수 있다. 중등도 이상의 췌장염에서는 활동성 염증반응이 가라앉은 뒤에, 특히 가성낭종이나 체액 고임이 있는 경우 약 6 주 뒤로 담낭절제술을 미루어 시행하는 것이 이환율 감소에 유리하다. 담낭절제술을 받기에 부적절한 환자에서는 내시경 괄약근절개술이 재발성 췌장염을 줄이는데 도움이 될 수 있다. 그러나 내시경 괄약근
절개술을 시행한 환자의 경우에도 담낭절제술을 추가로 시행하는 것이 재발성 췌장염의 위험을 더욱 감소시키므로 가능하다면 담낭절제술을 시행하는 것이 추천된다.

국문 색인: 담석성 췌장염, 내시경적 역행성 담췌관 조영술, 담낭절제술, 적응증, 시점

\section{Conflicts of Interest}

The authors have no financial conflicts of interest.

\section{REFERENCES}

1. Tenner S, Baillie J, DeWitt J, Vege SS; American College of Gastroenterology. American College of Gastroenterology guideline: management of acute pancreatitis. Am J Gastroenterol 2013;108:14001415;1416.

2. Curran FT, Neoptolemos JP. Acute biliary pancreatitis. Ann Ital Chir 1995;66:197-202.

3. Moreau JA, Zinsmeister AR, Melton LJ 3rd, DiMagno EP. Gallstone pancreatitis and the effect of cholecystectomy: a population-based cohort study. Mayo Clin Proc 1988;63:466-473.

4. Jones BA, Salsberg BB, Mehta MH, Bohnen JM. Common pancreaticobiliary channels and their relationship to gallstone size in gallstone pancreatitis. Ann Surg 1987;205:123-125.

5. Lerch MM, Adler G. Experimental animal models of acute pancreatitis. Int J Pancreatol 1994;15:159-170.

6. Lévy $P$, Boruchowicz $A$, Hastier $P$, et al. Diagnostic criteria in predicting a biliary origin of acute pancreatitis in the era of endoscopic ultrasound: multicentre prospective evaluation of 213 patients. Pancreatology 2005;5:450-456.

7. van Santvoort HC, Besselink MG, de Vries AC, et al. Early endoscopic retrograde cholangiopancreatography in predicted severe acute biliary pancreatitis: a prospective multicenter study. Ann Surg 2009;250:6875 .

8. da Costa DW, Bouwense SA, Schepers NJ, et al. Same-admission versus interval cholecystectomy for mild gallstone pancreatitis (PONCHO): a multicentre randomised controlled trial. Lancet 2015;386:12611268.

9. Frossard JL, Hadengue A, Amouyal G, et al. Choledocholithiasis: a prospective study of spontaneous common bile duct stone migration. Gastrointest Endosc 2000;51:175-179.

10. Cavdar F, Yildar M, Tellioğlu G, Kara M, Tilki M, Titiz MI. Controversial issues in biliary pancreatitis: when should we perform MRCP and ERCP? Pancreatology 2014;14:411-414.

11. Cotton PB, Lehman G, Vennes J, et al. Endoscopic sphincterotomy complications and their management: an attempt at consensus. Gastrointest Endosc 1991:37:383-393. 
12. Loperfido S, Angelini G, Benedetti G, et al. Major early complications from diagnostic and therapeutic ERCP: a prospective multicenter study. Gastrointest Endosc 1998;48:1-10.

13. Frei GJ, Frei VT, Thirlby RC, McClelland RN. Biliary pancreatitis: clinical presentation and surgical management. Am J Surg 1986;151:170175.

14. Sandzén B, Haapamäki MM, Nilsson E, Stenlund HC, Oman M. Cholecystectomy and sphincterotomy in patients with mild acute biliary pancreatitis in Sweden 1988 - 2003: a nationwide register study. BMC Gastroenterol 2009;9:80.

15. Nguyen GC, Rosenberg M, Chong RY, Chong CA. Early cholecystectomy and ERCP are associated with reduced readmissions for acute biliary pancreatitis: a nationwide, population-based study. Gastrointest Endosc 2012;75:47-55.

16. van Geenen EJ, van der Peet DL, Mulder CJ, Cuesta MA, Bruno MJ. Recurrent acute biliary pancreatitis: the protective role of cholecystectomy and endoscopic sphincterotomy. Surg Endosc 2009;23:950-956.

17. Neoptolemos JP, Carr-Locke DL, London NJ, Bailey IA, James D, Fossard DP. Controlled trial of urgent endoscopic retrograde cholangiopancreatography and endoscopic sphincterotomy versus conservative treatment for acute pancreatitis due to gallstones. Lancet 1988;2:979-983.

18. Acosta JM, Katkhouda N, Debian KA, Groshen SG, Tsao-Wei DD, Berne TV. Early ductal decompression versus conservative management for gallstone pancreatitis with ampullary obstruction: a prospective randomized clinical trial. Ann Surg 2006;243:33-40.

19. Fölsch UR, Nitsche R, Lüdtke R, Hilgers RA, Creutzfeldt W. Early ERCP and papillotomy compared with conservative treatment for acute biliary pancreatitis. The German Study Group on acute biliary pancreatitis. N Engl J Med 1997;336:237-242.

20. Oría A, Cimmino D, Ocampo C, et al. Early endoscopic intervention versus early conservative management in patients with acute gallstone pancreatitis and biliopancreatic obstruction: a randomized clinical trial. Ann Surg 2007;245:10-17.

21. Tse F, Yuan Y. Early routine endoscopic retrograde cholangiopancreatography strategy versus early conservative management strategy in acute gallstone pancreatitis. Cochrane Database Syst Rev 2012;(5):CD009779.

22. Wada K, Takada T, Kawarada Y, et al. Diagnostic criteria and severity assessment of acute cholangitis: Tokyo guidelines. J Hepatobiliary Pancreat Surg 2007;14:52-58.

23. Vege SS, DiMagno MJ, Forsmark CE, Martel M, Barkun AN. Initial medical treatment of acute pancreatitis: American Gastroenterological Association Institute technical review. Gastroenterology 2018;154:1103-1139.
24. Crockett SD, Wani S, Gardner TB, Falck-Ytter Y, Barkun AN, American Gastroenterological Association Institute Clinical Guidelines Committee. American Gastroenterological Association Institute guideline on initial management of acute pancreatitis. Gastroenterology 2018;154:1096-1101.

25. Fan ST, Lai EC, Mok FP, Lo CM, Zheng SS, Wong J. Early treatment of acute biliary pancreatitis by endoscopic papillotomy. N Engl J Med 1993;328:228-232.

26. ASGE Standards of Practice Committee, Maple JT, Ben-Menachem T, et al. The role of endoscopy in the evaluation of suspected choledocholithiasis. Gastrointest Endosc 2010;71:1-9.

27. Yadav D, O'Connell M, Papachristou GI. Natural history following the first attack of acute pancreatitis. Am J Gastroenterol. 2012;107:10961103.

28. van Baal MC, Besselink MG, Bakker OJ, et al. Timing of cholecystectomy after mild biliary pancreatitis: a systematic review. Ann Surg 2012;255:860-866.

29. Hwang SS, Li BH, Haigh PI. Gallstone pancreatitis without cholecystectomy. JAMA Surg 2013;148:867-872.

30. Kelly TR, Wagner DS. Gallstone pancreatitis: a prospective randomized trial of the timing of surgery. Surgery 1988;104:600-605.

31. Nealon WH, Bawduniak J, Walser EM. Appropriate timing of cholecystectomy in patients who present with moderate to severe gallstoneassociated acute pancreatitis with peripancreatic fluid collections. Ann Surg 2004;239:741-749; discussion 749-751.

32. Lee SP, Nicholls JF, Park HZ. Biliary sludge as a cause of acute pancreatitis. N Engl J Med 1992;326:589-593.

33. Garg PK, Tandon RK, Madan K. Is biliary microlithiasis a significant cause of idiopathic recurrent acute pancreatitis? A long-term followup study. Clin Gastroenterol Hepatol 2007;5:75-79.

34. Räty S, Pulkkinen J, Nordback I, et al. Can laparoscopic cholecystectomy prevent recurrent idiopathic acute pancreatitis?: a prospective randomized multicenter trial. Ann Surg 2015;262:736-741.

35. Mustafa A, Begaj I, Deakin M, et al. Long-term effectiveness of cholecystectomy and endoscopic sphincterotomy in the management of gallstone pancreatitis. Surg Endosc 2014;28:127-133.

36. Zhou MQ, Li NP, Lu RD. Duodenoscopy in treatment of acute gallstone pancreatitis. Hepatobiliary Pancreat Dis Int 2002;1:608-610.

37. Chen $P$, Hu B, Wang C, Kang Y, Jin X, Tang C. Pilot study of urgent endoscopic intervention without fluoroscopy on patients with severe acute biliary pancreatitis in the intensive care unit. Pancreas 2010;39:398-402.

38. Yang P, Feng KX, Luo H, Wang D, Hu ZH. Acute biliary pancreatitis treated by early endoscopic intervention. Panminerva Med 2012;54:65-69. 